\title{
A resposta da Universidade Federal da Bahia para o fortalecimento do enfrentamento da COVID-19 no município de Vitória da Conquista
}

\section{The response of the Universidade Federal da Bahia to strengthen the confrontation of COVID-19 in the municipality of Vitória da Conquista}

\author{
Angélica Ferraz. Gomes \\ Francine Cristina Silva Rosa ${ }^{2}$ \\ Guilherme Barreto Campos ${ }^{3}$ \\ Edi Cristina Manfroit
}

Resumo: O objetivo do estudo foi relatar a construção de ações pela Universidade Federal da Bahia, Campus Anísio Teixeira, com o intuito de fortalecer a resposta ao enfrentamento da Covid-19 pelo município de Vitória da Conquista, Bahia. As ações compreenderam o reforço aos suprimentos de Equipamento de Proteção Individual (EPIs) e Coletiva (EPCs), implementação de artifícios de Biossegurança para a desinfecção, apoio a testagem e diagnóstico e apoio psicológico. O presente relato revelou que o apoio da Universidade Federal da Bahia, campus de Vitória da Conquista, no enfrentamento da pandemia, contribuiu de maneira significativa nas diversas ações supracitadas, ratificando a importância da universidade na comunidade.

Palavras-chave: Apoio psicológico. Biossegurança. Covid-19. Desinfecção; Universidade.

Abstract: This study aimed to report the construction of actions by Universidade Federal da Bahia, Anísio Teixeira campus, in order to strengthen the response to the confrontation with Covid-19 by the municipality of Vitória da Conquista, Bahia. The activities included strengthening the supply of individual (IPE) and collective (CPE) protective equipment, implementing Biosafety devices for disinfection; support for testing and diagnosis and psychological support. The present report revealed that the help of the Universidade Federal da Bahia, Vitória da Conquista campus, in facing the pandemic contributed significantly to the various actions mentioned above, confirming the importance of the university in the community.

Keywords: Psychological support. Biosafety. Covid-19. Disinfection. University.

\footnotetext{
${ }^{1}$ Doutora em Química Orgânica (UFBA- Universidade de Innsbruck, Áustria). Mestre em Química Analítica (UESB). Docente do IMS-CAT-UFBA. Linha de pesquisa: Química de Produtos Naturais. E-mail: licaferraz@yahoo.com.br

2 Pós-Doutorado em Física Óptica e Ciências dos Materiais no IFSC-USP. Doutora e Mestre pela Universidade Estadual Paulista (UNESP) de São José dos Campos-SP. Docente do Programa de Pós-Graduação em Biociências do Instituto Multidisciplinar em Saúde da Universidade Federal da Bahia (IMS-UFBA). Coordenadora da Comissão de Biossegurança do IMS-UFBA. E-mail: franmicro@ufba.br

${ }^{3}$ Doutorado e Mestrado em Microbiologia pela Universidade de São Paulo (USP). Docente do IMS-CAT-UFBA. Email: guilhermebcampos@ufba.br

4 Pós-doutorado em Psicologia: cognição e comportamento pela UFMG (2019). Doutorado pela UFSC Universidade Federal de Santa Catarina. Docente dos cursos de graduação de Psicologia e do Mestrado Profissional em Psicologia da Saúde. Docente do IMS-CAT-UFBA. E-mail: edicristinam@gmail.com
} 


\section{Introdução}

A Covid-2019 foi relatada pela primeira vez em Wuhan, China, no final de 2019. Desde então, o surto se espalhou rapidamente para outras províncias do continente na China e outros países do mundo. Atualmente, o número de pessoas diagnosticado com infecção por Covid-19 está aumentando drasticamente. Em 11 de março de 2020, a Organização Mundial da Saúde (OMS) declarou oficialmente a pandemia por Covid-19. A partir desta data, muitos países começaram a adotar medidas de isolamento social com a finalidade de minimizar o avanço da doença. No Brasil, as instituições de ensino paralisaram suas atividades desde meados do mês de março e diversos estabelecimentos comerciais também suspenderam suas atividades. Infelizmente, até o momento, nenhum medicamento ou vacina foram aprovados pelas agências reguladoras para o tratamento da Covid-19, o que torna ainda mais desafiador o combate desta pandemia.

O enfrentamento da pandemia do novo coronavírus faz parte das funções essenciais da Saúde Pública por meio de ações voltadas para a população ou para grupos com maior risco de contaminação, como os profissionais de saúde. Nesse sentido, as universidades podem ter um papel relevante na disseminação e na capacitação dos atores sociais e serviços para o enfrentamento da crise sanitária. Frente a esse cenário, diversas Universidade e Institutos Federais no Brasil têm de alguma forma auxiliado suas respectivas comunidades locais no enfrentamento da pandemia, não somente na pesquisa (desenvolvimento de vacinas, medicamentos e teste diagnósticos) como também na produção de respiradores, álcool 70\%, máscaras e protetores faciais, capacitação de recursos humanos e etc. No Instituto Multidisciplinar de Saúde da Universidade Federal da Bahia, campus de Vitória da Conquista (IMS-CAT-UFBA), diversas atividades foram realizadas por alguns grupos de docentes e técnicos com o objetivo de colaborar no enfrentamento da pandemia no município. As ações envolveram tanto suporte material como produção de EPIs (Equipamentos de Proteção Individual), EPCs (Equipamentos de Proteção Coletiva), produção de álcool 70\%, implementação de artifícios de Biossegurança para a desinfecção, apoio técnico para desenvolvimento de tecnologias, como também apoio aos serviços de saúde tais como suporte na realização dos testes para Covid-19, capacitação de recursos humanos e apoio psicológico. Esse trabalho tem como objetivo relatar essas experiências no enfrentamento ao COVD-19 no município de Vitória da Conquista, Bahia.

\section{Aspectos metodológicos}

Trata-se de um relato de experiência oriundo de ações realizadas por docentes e técnicos do (IMSCAT-UFBA). Com o advento da pandemia provocada pelo novo coronavírus (nCoV-2019), diversas Universidades e Institutos Federais começaram a se mobilizar com o intuito de auxiliar suas respectivas comunidades locais no combate à pandemia. O nosso Instituto ao perceber essa demanda iniciou um processo espontâneo de suporte à comunidade e a diversos segmentos dos serviços públicos de saúde do 
município. Algumas dessas iniciativas ocorreram em função de demandas levadas pelos serviços de saúde à Universidade como a produção de álcool 70\% e o suporte na realização do diagnóstico. Outras foram iniciativas de alguns grupos de docentes como o atendimento psicológico e o apoio técnico para o desenvolvimento de tecnologias voltadas a se evitar a disseminação do vírus entre os profissionais de saúde e na comunidade.

\section{Reforço à cadeia de suprimentos}

Produção de álcool $70 \%$

Com o advento da pandemia, houve uma grande demanda por alguns suprimentos, tais como álcool 70\% e álcool em gel, máscaras, respiradores etc. Essa grande demanda ocasionou uma falta no mercado mundial dos mesmos, dificultando o acesso da população. $\mathrm{O}$ uso de degermantes como álcool $70 \%$ e álcool em gel e as máscaras pela população foram recomendados como forma de prevenir a transmissão da Covid-19. Diante da escassez destes suprimentos e da necessidade de auxiliar na proteção da população, alguns segmentos do serviço de saúde municipal solicitaram ao nosso instituto auxílio para atender tal demanda.

Nessa ocasião, o álcool 70\% e o álcool em gel estavam praticamente esgotados no mercado e os poucos fornecedores estavam praticando preços exorbitantes em função da escassez. Em função desta situação, a Agência Nacional de Vigilância Sanitária (ANVISA) publicou a RDC 350 (ANVISA, 2020a) que define os critérios e os procedimentos extraordinários e temporários para a fabricação e comercialização de preparações antissépticas ou sanitizantes oficinais sem prévia autorização da Anvisa. Esta Resolução abriu a possibilidade de se realizar o preparo de álcool 70\% em alguns laboratórios, como em universidades, por exemplo, em caráter emergencial. Diante deste cenário, um grupo de três professores (Dr. Juliano Geraldo Amaral, Dr. Anderson Santos Souza e Dra. Angélica Ferraz Gomes) e um técnico de laboratório (Msc. Robson França) (Figura 1) se voluntariaram para atender à demanda de alguns municípios da região Sudoeste da Bahia (Vitória da Conquista e Anagé). 


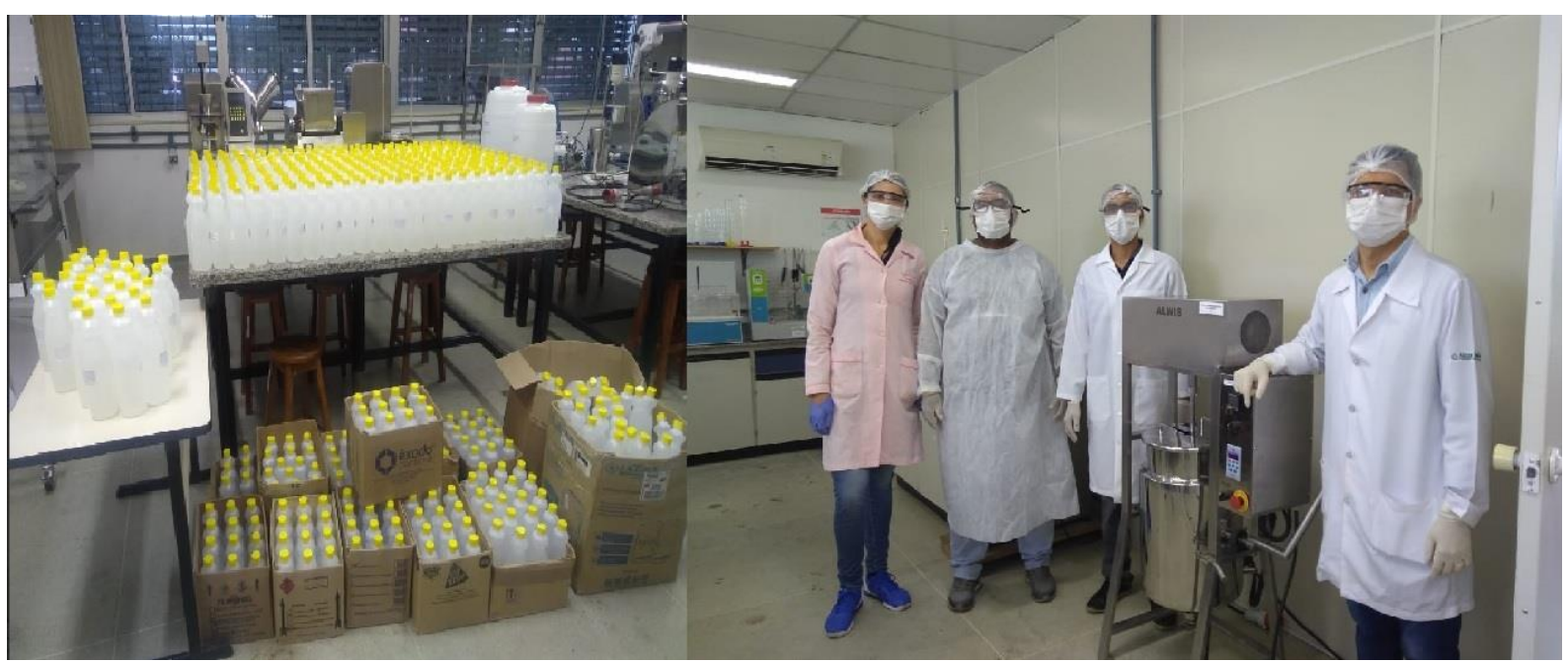

Figura 1: Produção de álcool 70\% e grupo responsável (Profa. Dra. Angélica Ferraz Gomes, Técnico de Laboratório Msc. Robson França, Prof. Dr. Anderson Santos Souza e Prof. Dr. Juliano Geraldo Amaral).

Essas prefeituras possuíam em seus estoques o álcool etílico em concentrações superiores a 70\%, tais como $99,5^{\circ}$ INPM e $96^{\circ}$ GL por exemplo, que são inadequados para serem utilizados como antissépticos. Nestas referidas concentrações, o álcool etílico além de evaporar rapidamente (o que não permite o contato com o vírus tempo suficiente para ser eficaz), a baixa concentração de água também limita a permeação do álcool etílico no microrganismo. Desta forma, esse grupo de professores juntamente com o técnico de laboratório realizaram a diluição deste álcool de concentração mais elevada para a concentração de 70\%, mais eficaz. Essas atividades foram realizadas no Laboratório de Tecnologia Farmacêutica do nosso Instituto. Esse laboratório possui equipamentos industriais de pequena escala, os quais permitiram a produção e o envase de mais de dois mil litros de álcool 70\% para esses municípios. O álcool $70 \%$ produzido por esse grupo foi disponibilizado para as respectivas prefeituras, as quais realizaram a distribuição para as Unidades Básicas de Saúde e para os agentes de saúde do município.

Esse tipo de ação não foi somente realizada pelo nosso Instituto, diversas Universidades (UESB, UNIFAP, UFF, UEPG, UFPE etc.) e Institutos Federais (IFSP, IFRR, IFC, IF Baiano, etc.) realizaram ações parecidas na produção de álcool 70\% e também álcool em gel. A partir da nossa experiência, que foi divulgada em matérias das emissoras de televisão local tais como TV Sudoeste (G1, 2020a), TV Aratu, TV UESB e TV Record, página do (IMS, 2020a) bem como em redes sociais, a Universidade Estadual de Feira de Santana (UEFS), dentre outras, entrou em contato com nosso grupo para que relatássemos nossas experiências. Esses relatos viabilizaram esse mesmo tipo de ação no município de Feira de SantanaBa. Foi uma troca de experiências muito enriquecedora com a professora Dra. Tatiane Alencar (UEFS), a qual foi responsável por realizar a fabricação de álcool 70\% glicerinado no laboratório de Farmacotécnica do curso de Farmácia da UEFS. Foi muito gratificante para o nosso grupo poder ter auxiliado de alguma forma nosso município no combate ao nCoV-2019, demonstrando o papel da Universidade na comunidade local. 
Apoio técnico para o desenvolvimento de máscaras faciais (Face-shield)

Os protetores faciais são equipamentos de proteção individual (EPI's) essenciais para evitar o contágio da Covid-19 entre os profissionais de saúde que atendem pacientes contaminados. São artifícios mecânicos de materiais plásticos de fácil higienização e desinfecção que configuram uma proteção extra às máscaras N95, ao evitar que aerossóis ou respingos contaminados alcancem as mucosas oculares, respiratórias ou orais desses profissionais. Com o avança da epidemia no Brasil, vários HUB's, ou seja, grupos de trabalhos criados através de aplicativo de mensagens foram movimentando-se a fim de proporcionar condições de desenvolvimento de métodos alternativos de produção de protetores faciais (face-shield) para serem doados principalmente aos profissionais de saúde que estariam em atuação nos hospitais e centros de saúde atendendo diretamente os pacientes suspeitos e confirmados com Covid-19. A exemplo dos HUB's de outros países e de outros Estados brasileiros, o HUB Combate-Covid-VCA, formado por docentes das universidades públicas e particulares da cidade de Vitória da Conquista, profissionais da tecnologia, empresários, profissionais de saúde, representantes das maçonarias da cidade e voluntários, criaram uma rede de apoio para elaboração e desenvolvimento dos protetores faciais (faceshield) em impressoras 3D e de corte a LASER, assim como elaboraram logística para o levantamento da necessidade regional e captação de recurso necessário para a aquisição dos materiais. Tudo foi realizado e combinado de uma maneira eficiente por aplicativo de mensagens e, extraordinariamente, mais de 3.000 protetores foram entregues aos profissionais de saúde de Vitória da Conquista e região em atendimento aos casos suspeitos e confirmados de Covid-19, aos profissionais que atuam nos centros diagnósticos, aos socorristas dos SAMU's, aos profissionais do Instituto Médico Legal (IML), aos profissionais das unidades de atendimento de saúde municipais, entre outros. Nessa ação, os docentes do IMS/UFBA, Prof ${ }^{a}$ Doutora Francine Cristina Silva Rosa e Prof. Doutor Luciano Pereira Rosa, estiveram diretamente envolvidos em todas as etapas do processo. A ação foi reportada pela TV-UFBA (EDGARDIGITAL, 2020) e pela TV local, TV Sudoeste, afiliada da rede Globo, no dia 26 de abril de 2020.

\section{Apoio técnico para o desenvolvimento e utilização de túneis de desinfecção}

Em parceria com empresa de audiovisual P7 de Vitória da Conquista e as Lojas Maçônicas Fraternidade Conquistense e Cavaleiros do Oriente, foi desenvolvido um túnel de desinfecção para doação aos hospitais da cidade (HGVC, Esaú e São Vicente). O túnel tem por objetivo realizar a desinfecção dos paramentos dos profissionais de saúde imediatamente após o atendimento dos pacientes com Covid-19 com o objetivo de diminuir a chance de contágio durante o procedimento de desparamentação, já que esse é um dos momentos de maior contaminação dos profissionais de saúde.

Os professores do IMS/UFBA, Dra Francine Cristina Silva Rosa e Dr. Luciano Pereira Rosa, contribuíram através de assessoria técnico-científica para que o projeto de construção do túnel ficasse mais adequado às condições de desinfecção objetivada pelo método de Biossegurança para que pudesse ser adequadamente instalado dentro dos hospitais (Figura 2). Em visita ao Hospital Geral de Vitória da 
Conquista (HGVC), foram observadas as adequações e discutidas as melhores formas de utilização do equipamento para que os profissionais fossem realmente beneficiados pelo método.

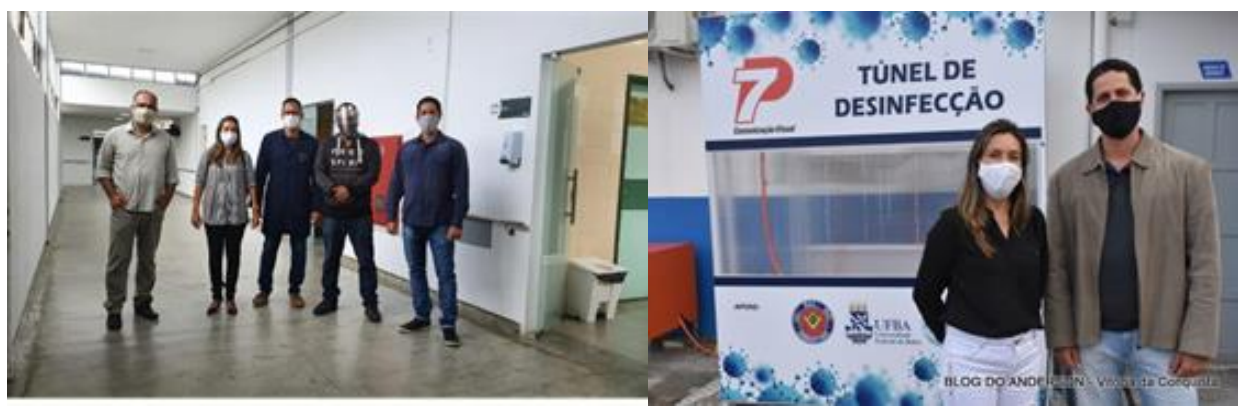

Figura 2: Foto da esquerda: Equipe de desenvolvimento do túnel de desinfecção onde estão os professores Dra Francine e Dr. Luciano com o Engenheiro do Hospital Geral de Vitória da Conquista em visita técnica; Foto da direita: Professores Dr $^{a}$ Francine e Dr. Luciano na entrega do túnel de desinfecção ao Hospital São Vicente em Vitória da Conquista.

O equipamento funciona através da nebulização de uma solução de baixa concentração de hipoclorito de sódio diluído em água que recai sobre os paramentos dos profissionais de saúde assim que eles entram e permanecem dentro do túnel por um tempo aproximado de 15-20 segundos, tempo suficiente para que o risco de contágio durante a desparamentação seja reduzido. Apesar da Nota Técnica $\mathrm{n}^{\circ} 38$ publicada pela Anvisa alertar que não foram encontradas evidências científicas de que o uso dessas estruturas para desinfecção seja eficaz no combate ao SARS-CoV-2, novos estudos poderiam modificar este posicionamento, a qualquer momento. Segundo a Anvisa, é possível o uso de saneantes, desde que tenha a eficácia testada e que os profissionais de saúde utilizem equipamentos de segurança individuais (máscaras, capotes ou capas, botas, entre outros) que impeçam o contato do produto químico desinfetante com a pele, olhos e mucosas (ANVISA, 2020b).

Os professores também estão apoiando o desenvolvimento de um modelo de túnel para ser utilizado na comunidade, tanto em centros onde há maior circulação de pessoas, quanto em bancos, shoppings, supermercados, entre outros estabelecimentos. Também, em parceria com o SENAICIMATEC de Salvador e outros colaboradores, os professores Francine e Luciano pretendem realizar pesquisas para a definição dos melhores e mais eficazes métodos de desinfecção para serem associados a esses túneis em diferentes situações. A ação foi reportada na página institucional do IMS-CAT-UFBA (IMS, 2020b) pela TV Sudoeste e teve transmissão ao vivo na TV Bahia, com sede em Salvador, em nível estadual, filiada da Rede Globo de Televisão, em 7 de maio de 2020. Também foi noticiada em blogs de ampla divulgação na cidade de Vitória da Conquista-BA, como o Blog do Anderson (2020) do dia 26 de maio. 
Criação de programa de capacitação de profissionais de higienizaçãa e serviços gerais de Hospitais da cidade de Vitória da Conquista e região

Foi realizado um programa de "Capacitação em Biossegurança e Higienização em tempos de Covid-19" para profissionais de higienização e serviços gerais direcionados exclusivamente a Hospitais que realizam atendimento de pacientes suspeitos ou confirmados com Covid-19. Nesse programa, desenvolvido e ministrado pela Profa. Dra. Francine Cristina S. Rosa, do IMS/UFBA, os profissionais recebem orientação sobre os cuidados estabelecidos nas normas da ANVISA para os procedimentos de higienização de locais, superfícies e equipamentos onde realiza-se o atendimento ao paciente dentro do serviço de saúde. Orientações sobre os EPI's corretos, materiais, desinfetantes e procedimentos de Biossegurança inerentes aos profissionais são discutidos de forma minuciosa através da capacitação realizada em formato remoto. Até o momento, foram realizadas duas capacitações no Hospital da cidade de Tremedal-BA.

\section{Fluxos de triagem, atendimento e testes de diagnóstico}

\section{Habilitação do diagnóstico molecular da Covid-19}

Em fevereiro de 2020, o Ministério da Saúde (MS) declarou Emergência em Saúde Pública de Importância Nacional (ESPIN), em decorrência da infecção humana pelo novo coronavírus MS (2020a). Cerca de um mês depois reconheceu a transmissão comunitária do novo coronavírus no Brasil (MS, 2020b) e solicitou esforços de todos os gestores nacionais na adoção de medidas que contribuíssem para o controle da pandemia em nível local e nacional.

O Ministério da Saúde estabeleceu que a coleta de amostras, exame e testes laboratoriais necessários para identificação do coronavírus, bem como as medidas de biossegurança deviam observar as diretrizes estabelecidas pelo próprio Ministério da Saúde. Além disso, o credenciamento de laboratórios públicos e privados foi condicionado à validação por laboratórios de referência em âmbito nacional (MS, 2020c). Assim, em abril, a Secretaria da Saúde do Estado da Bahia (SESAB), por meio do Laboratório Central de Saúde Pública Professor Gonçalo Moniz (LACEN/BA) divulgou nota técnica com as orientações para habilitação de laboratórios para o diagnóstico molecular da Covid-19 no estado (ANVISA, 2020b).

Diante da emergência da pandemia, a Universidade Federal da Bahia contatou a Secretaria Municipal de Saúde para estabelecer parceria e aumentar a capacidade de testagem da população local (IMS, 2020c). A Universidade emprestou diferentes equipamentos (Equipamento de PCR em tempo real, Centrífuga Spin, Centrífuga de Placas, Capelas de Fluxo Laminar, Microcentrífuga refrigerada e agitadores do tipo Vórtex) para uso enquanto durar o estado de emergência. Em contrapartida, o LACEN local adaptou e destinou espaço exclusivo para a rotina de biologia molecular (testes de DNA) dedicado ao 
diagnóstico da Covid-19. Após a estruturação do espaço, o Prof. Dr. Guilherme Barreto Campos e o Prof. Dr. Lucas Miranda Marques realizaram treinamento in loco da equipe para uso do aparelho de PCR em tempo real e de seu software (Step One Plus - Applied Biosystems) IMS (2020d). Além disso, foram discutidos protocolos de boas práticas laboratoriais e medidas de biossegurança com a equipe. Após esta fase, foram produzidos vídeos tutoriais sobre o uso da plataforma de PCR em tempo real, para consulta pela equipe, e prestada consultoria remota no período de adaptação da rotina laboratorial. Após habilitação, o LACEN de Vitória da Conquista se tornou o primeiro laboratório do interior do estado a realizar a rotina de diagnóstico molecular da Covid-19 (G1, 2020b). O LACEN municipal recebe hoje amostras de mais de 30 municípios da região sudoeste. Assim, em pouco mais de um mês de implementação da testagem molecular no município, foram realizados 950 testes com 163 resultados positivos.

Diante do cenário epidêmico e dos comunicados oficiais, a articulação da universidade com gestores públicos foi determinante para habilitação do diagnóstico molecular em Vitória da Conquista. Em reuniões virtuais entre gestores, pesquisadores e profissionais da saúde, foi discutido o uso racional dos testes moleculares. Foi consenso que as orientações seguissem critérios técnicos e científicos amparados também nos protocolos do Ministério da Saúde. Assim, foi recomendada a abordagem por meio da busca ativa como ponto de partida de investigação de todos os contactantes dos casos de Covid-19 já confirmados. Foi orientado o uso do teste de PCR em tempo real a partir de amostra de swab oral/nasal coletada em até 7 dias após o início dos sintomas ou o uso do teste imunológico (teste rápido por imunocromatografia ou sorologia por ELISA) após 7 dias do início dos sintomas. Para os assintomáticos, recomenda-se a coleta baseado na quantidade de dias referidos após o contato com a pessoa infectada: $<7$ dias (qPCR) e $\geq 7$ dias (imunológico). No momento, o principal desafio é o acesso ao material necessário para os testes. A dificuldade deve-se à procura global pelos insumos e ao número limitado de empresas nacionais fornecedoras. O Brasil ainda depende da importação de muitos reagentes (BARIFOUSE, 2020).

\section{Apoio aos profissionais de saúde e comunidade quanto à saúde mental através do Plantão Psicológico Online}

O curso de graduação em Psicologia e o Programa de Pós-Graduação em Psicologia da Saúde do IMS-CAT -UFBA delinearam uma proposta de atendimento psicossocial mediada por TICs (Tecnologia da Informação e Comunicação). No Brasil, o atendimento psicológico mediado por TICs é regulamentado pela Resolução do Conselho Federal de Psicologia (CFP) n ${ }^{\circ}$ 11, de 11 de maio de 2018 (CFP, 2018). Diante da pandemia de Covid-19, essas vedações foram suspensas pela Resolução CFP no 4, de 26 de março de 2020 (CFP, 2020), bastando apenas o cadastro no e-Psi e a inscrição ativa no Conselho. Cabe, portanto, à categoria elaborar alternativas inovadoras de intervenção usando essa ferramenta. Foi nesse contexto que o Plantão Psicológico Online foi proposto.

O Plantão Psicológico, enquanto uma modalidade clínica contemporânea, caracteriza-se por realizar atendimentos psicoterapêuticos de caráter emergencial destinados à comunidade que a ele recorre 
espontaneamente, sem a necessidade de agendamento prévio, cuja função é proporcionar uma escuta e um acolhimento à pessoa no momento de crise (REBOUÇAS; DUTRA, 2010). O Plantão Psicológico é uma das modalidades oferecidas pelo Serviço de Psicologia da UFBA-IMS e já atendeu um total de 366 pessoas durante o ano de 2019. Com a necessidade de manter distanciamento físico, não foi possível manter a mesma estrutura do Plantão Psicológico na sua concepção, passando da modalidade presencial e procura espontânea, para o formato online e agendada, mas mantendo o foco dos atendimentos em seu caráter emergencial tendo como função oferecer uma escuta de acolhimento em momento de crise, visto que o tempo entre agendamento e o atendimento tem ocorrido no prazo máximo de dez dias.

O atendimento é oferecido para adultos acima de 18 anos da comunidade de Vitória da Conquista e região e tem prioridade os profissionais de saúde, na medida que se entende que eles atuam na linha de frente do combate à Covid-19 e, que, encontram-se potencialmente suscetíveis a apresentarem sofrimento psíquico decorrente do risco e responsabilidade atrelados a esta função, e membros da comunidade que aguardam o resultado do exame da Covid-19 pelo alto índice de ansiedade gerado pela espera. O foco dos atendimentos são os problemas psicológicos desencadeados pela Pandemia da Covid-19. Questões que exigem atenção de outros profissionais, como no caso de acompanhamento psiquiátrico, são referenciados para o CAPS II do município, quando o caso também reside na cidade de Vitória da Conquista. O projeto conta com quatro docentes, seis psicólogos alunos do mestrado profissional de psicologia da saúde e mais 13 psicólogos alunos de outra instituição parceira do projeto. Os plantonistas passaram por um treinamento virtual com o objetivo de capacitar quanto ao modelo de atendimento online através de um protocolo que foi delineado para essa finalidade. O plantão teve início em maio de 2020 e atendeu mais de 60 pessoas em 30 dias de funcionamento.

O Projeto Plantão Psicológico tem trazido várias experiências no ambiente online. Uma delas, e talvez a principal, é a de propiciar um suporte terapêutico para pessoas que apresentam um aumento da ansiedade, estresse, apatia, depressão, ociosidade, incerteza quanto ao mundo do trabalho e medo de contrair o vírus. $\mathrm{Na}$ experiência de supervisão aos plantonistas, é possível notar como muitas vezes uma demanda anterior, por exemplo, de ansiedade acaba se avolumando como resposta de enfrentamento ao Covid-19. Intervenções empáticas e de acolhimento do plantonista acaba por contribuir na construção de novas formas de enfrentamento para lidar com as situações no "aqui-e-agora". Dessa forma, o plantão tem se constituído como uma oportunidade de encontrar/desenvolver com o usuário novas formas de enfrentamento não só frente ao coronavírus como de outras situações que estavam pendentes anteriormente. Apesar do bom desempenho do plantão, os plantonistas e usuários enfrentam várias questões relacionadas às TICs: interrupção na conexão da internet, travamento de imagens, não conhecimento do uso do navegador, dificuldade com os dispositivos de microfone/câmeras, entre outras.

Os resultados até aqui nos indicam o potencial do Plantão Psicológico na modalidade online, mas também a necessidade de investir na formação profissional e no aprimoramento de novas tecnologias para 
essa finalidade. Os resultados da pesquisa que está sendo realizada concomitantemente ao plantão poderão contribuir com essas dificuldades.

\section{Considerações finais}

Nos últimos dois anos, as universidades públicas vêm enfrentando diversos problemas desde o contingenciamento de verbas (defendido com o argumento que as universidades são caras), comentários que as universidades públicas brasileiras produziriam pesquisa de baixa qualidade até a disseminação de notícias falsas as quais comprometem a reputação das instituições de ensino superior. As universidades requerem de fato um grande investimento financeiro para cumprir suas funções, pois muitas delas mantêm hospitais universitários e realizam diversos serviços de extensão, além de formar professores e pesquisadores altamente qualificados e realizar pesquisas nas mais diversas áreas do conhecimento. Essa distorção da imagem da universidade perante alguns segmentos da população é extremamente preocupante, que parecem não compreender a importância das universidades para a sociedade. Com o surgimento da pandemia, as universidades estão tendo a oportunidade de mostrar de maneira mais explícita o seu papel e a sua importância. As ações que foram desenvolvidas não apenas no nosso Instituto, mas em diversas instituições públicas de ensino superior, vêm desmistificar essa concepção equivocada sobre a relevância da universidade na sociedade brasileira. Neste contexto da pandemia, as universidades vêm desempenhando um papel crucial para o enfrentamento da mesma, tanto no campo da pesquisa como em atividades de extensão.

Agradecimentos: Nossos agradecimentos aos demais docentes e técnicos que contribuíram para a realização dessas atividades: Nília Maria Prado, Robson França, Juliano Geraldo Amaral, Anderson Santos Souza, Lucas Miranda Marques, Sérgio Lízias Rocha, Lívia Botelho Felix, Rayana Santedicola Andrade, Luciano Pereira Rosa, Márcio Vasconcelos, Márcio Galvão.

\section{Referências}

ANVISA. RDC 350 - Agência Nacional de Vigilância Sanitária. Brasil, 2020a.

Nota técnica n. 38/2020/SEI/ COSAN/ GHCOS/ DIRE3/ ANVISA. Brasil, 2020b.

BARIFOUSE, R. Coronavírus: por que o Brasil ainda não conseguiu fazer testes em massa? Disponível em: <https://www.bbc.com/portuguese/brasil-52145795>. Acesso em: 20/6/2020.

BLOG DO ANDERSON. Enfrentamento da COVID-19: Santa Casa de Misericórdia de Vitória da Conquista conta com Túnel de Desinfecção. Disponível em:

$<$ https:/ / conquistatop.com.br/26/05/2020/enfrentamento-da-covid-19-santa-casa-de-misericordia-devitoria-da-conquista-conta-com-tunel-de-desinfeccao/vitoria-da-conquista $>$. Acesso em: 24/6/2020.

CFP. Resolução 11 de 11 de maio de 2018. 2018.

. Resolução n. 4, de 26 de março de 2020. 2020. 
EDGARDIGITAL. Impressoras 3D e solidariedade: grupos da UFBA atuam na produção de máscaras hospitalares. Disponível em: <http://www.edgardigital.ufba.br/?p=16522>. Acesso em: $24 / 6 / 2020$.

G1. Professores e técnicos da UFBA de Vitória da Conquista produzem álcool $70 \%$ para distribuir no setor de saúde da cidade. Disponível em:

<https://g1.globo.com/ba/bahia/noticia/2020/04/05/professores-e-tecnicos-da-ufba-de-vitoria-daconquista-produzem-alcool-70percent-para-distribuir-no-setor-de-saude-da-cidade.ghtml $>$. Acesso em: $24 / 6 / 2020$.

- Unidade do Lacen começa a funcionar em hospital de Vitória da Conquista para realização de testes de Covid-19. Disponível em: https://g1.globo.com/ba/bahia/noticia/2020/05/11/unidade-dolacen-comeca-a-funcionar-em-hospital-de-vitoria-da-conquista-para-realizacao-de-testes-de-covid19.ghtml. Acesso em: 23/6/2020.

IMS. Produção de álcool 70\% na UFBA-Conquista contribui com o combate ao COVID-19 nas unidades de saúde de Vitória da Conquista. 2020a. Disponível em:

$<$ http://www.ims.ufba.br/noticias/producao-de-alcool-70-na-ufba-conquista-contribui-com-o-combateao-covid-19-nas-unidades-de>. Acesso em: 24/6/2020.

Parceria entre UFBA-Conquista, Lojas maçônicas e empresa instalará túneis de desinfecção contra COVID-19 em hospitais de Vitória da Conquista. 2020b. Disponível em: $<$ Parceria entre UFBA-Conquista, Lojas maçônicas e empresa instalará túneis de desinfecção contra COVID-19 em hospitais de Vitória da Conquista>.

Parceria entre UFBA-Conquista e Secretaria Municipal de Saúde possibilitará testes mais rápidos de COVID-19. 2020c. Disponível em: http://www.ims.ufba.br/noticias/parceria-entre-ufbaconquista-e-secretaria-municipal-de-saude-possibilitara-testes-mais. Acesso em: 20/6/2020.

Professores da UFBA-Conquista ministram treinamento no Laboratório Central da Prefeitura Municipal para diagnostico da COVID-19. 2020d. Disponível em:

$<$ http://www.ims.ufba.br/noticias/professores-da-ufba-conquista-ministram-treinamento-no-laboratoriocentral-da-prefeitura $>$. Acesso em: 22/6/2020.

MS. Portaria n. 188, de 3 de fevereiro de 2020. Brasil: Diário Oficial da União, 2020a.

Portaria n. 454, de 20 de março de 2020. Brasil: Diário Oficial da União, 2020b.

Portaria n. 356, de 11 de março de 2020. Brasil: Diário Oficial da União, 2020c.

REBOUÇAS, M. S. S.; DUTRA, E. Plantão psicológico: uma prática clínica da contemporaneidade. Rev. abordagem gestál. (Impr.), v. 16, n. 1, p. 19-28, 2010. 